\title{
Empirical Analysis on Financial Distress Forecasting of Listed Companies in Jilin - Research based on Z-score Model
}

\author{
Shanshan $\mathrm{Yu}^{1}$, Lihua $\mathrm{Zhao}^{2}$ \\ ${ }^{1}$ School of Economics, Eastern Liaoning University, Dandong, China \\ ${ }^{2}$ School of Management, Liaoning Provincial College of Communications, Shenyang
}

\begin{abstract}
This article discusses the early warning model of financial crisis, considering our business practice. According to financial distress prediction model of existing listed companies, it applies the Fisher discriminant method in multivariate statistical, analyzes and forecasts the financial crisis of 31 listed companies in Jilin Province, and puts forward relevant policy recommendations, which make reference to the investment decisions of investors.
\end{abstract}

Index Terms - financial crisis prediction model, Z-score ratings, Fisher discriminant, financial risk

\section{Summarize Z-score Model}

Z-score model was proposed by a well-known financial expert Edward Altman in 1968. Basic principles of Z-score model are: First, using statistical methods, analysis the company's past financial indicators statistical, select the most predictive or analytical value ratio index to reflect the Company's financial condition. Secondly, using the selected ratio indicators, design a mathematical model to maximum distinguish financial position. Finally, this model helps to assess and distinguish the company's financial condition, and put financial condition of the enterprise into two categories: bankruptcy normal and risk categories. The basic steps of establishing $\mathrm{Z}$ value scoring model: first, select a group financial ratios to reflect the Company's financial position, such as the liquidity ratio, return on assets, solvency indicators, etc. The second step, collect sample data of the Company, and divide the sample into two categories: one is the samples of normal financial conditions; the other is the samples of bankruptcy trends. The third step, according to the degree of influencing on the financial situation of Various ratios, select Fisher, Bayes discriminant analysis, etc, establish linear discriminant function determined by the above ratio index , determine the affect weight of each ratio, then get a $Z$ value scoring model. The fourth step is analysis a series of $Z$ values of selected sample, get bankruptcy threshold and the $\mathrm{Z}$ region, which can measure the value of the financial position. The fifth step, put the company's relevant financial data in the model can get a $\mathrm{Z}$ value. If the score is higher than a certain threshold or a pre-determined range, you can determine that the company's financial condition is good; if less than a values, indicate that the company has the possibility of bankruptcy.

Z-score models according five financial ratios which established by Altman:

$Z=0.012 X_{1}+0.014 X_{2}+0.033 X_{3}+0.006 X_{4}+0.999 X_{5}(1)$
$\mathrm{X}_{1}$ = working capital / total assets, reflecting the liquidity; $\mathrm{X}_{2}=$ retained earnings / total assets, the cumulative profitability; $\mathrm{X}_{3}=\mathrm{EBIT} /$ total assets, reflecting the level of profitability of corporate assets; $\mathrm{X}_{4}=$ market value of equity / the book value of total liabilities, reflecting the degree of decline in the value of assets before its liabilities exceed its assets; $\mathrm{X}_{5}=$ sales / total assets, reflecting the capital turnover rate and sales capacity of the company. Altman calculated through statistical analysis and finalized borrowers default threshold $\mathrm{Z} 0=2.675$, if the $\mathrm{Z}<2.675$, borrowers are included in Default group; Conversely, if $Z \geq 2.675$, then the borrowers are classified as non-default group. When $1.81<\mathrm{Z}<2.99$, get larger misjudgment, the overlapping area is called "unknown zone" or "gray area."

According to financial indiators of eighty listed companies in 2012, this paper use Fisher discriminant analysis, build a model of financial distress which considering six aspects, including profitability, solvency, operation, capacity development, asset liquidity and the ability to receive cash, then test the model by chosing a random sample, finally applying this model analysis and forecast financial status of 31 listed companies in Jilin Province.

\section{Model and Analysis}

\section{A. Sample selection and data sources}

ST and * ST is an identification of financial crisis for listed company in the stock market of China. ST shares refers to the loss of domestic listed companies for two consecutive years by special treatment. ${ }^{*}$ ST shares of domestic listed companies refers to three consecutive losses. Domestic enterprises generally take whether ST as identification Standard of financial crisis in order to distinguish enterprise's financial situation. Considering changes of financial indicators and the timeliness of the selected data, the paper select the data of 2011 and 2012 for research.

This article divide the study sample data into three groups: (1)take datas of 80 listed companies(40 non-ST and 40 ST ) in Shanghai and Shenzhen as samples of establishing the Financial Distress Prediction model. (2)take datas of 20 randomly selected listed companies (10 ST and 10 non-ST) as samples of testing the Financial Distress Prediction mode. (3)take datas of 31 listed companies in Jilin Province as samples to be assessed. 


\section{B. Selected financial indicators}

Each researcher select different indicators, there isn't uniform standard for selecting financial Indicator of Financial Distress Prediction now. The indicators can basically reflect the company's financial health. According to the relevant literature, this paper selects seven financial indicators. There are six aspects: the solvency, profitability, operations, capacity development, asset liquidity and the ability to receive cash, which comprehensive response to the financial health of the enterprise.

The selected seven financial indicators are: Quick Ratio $\mathrm{X}_{1}$; ROA $\mathrm{X}_{2}$; total asset turnover $\mathrm{X}_{3}$; net profit growth $\mathrm{X}_{4}$; working capital utilization $\mathrm{X}_{5}$; operating cash flow per share $\mathrm{X}_{6}$; cash current liabilities ratio $\mathrm{X}_{7}$.

\section{Build financial risk prediction}

Take the selected seven indicators as model predictive variables, grouping category of the 40 non-ST listed companies is set to 0 , grouping category of the $40 \mathrm{ST}$ listed companies is set to 1, using SPSS 19.0 software and Fisher method, get Standardized canonical discriminant coefficient, Non-standardized discriminant coefficient and Classification function coefficients, Detailed in Table I, Table II, Table III:

TABLE I Standardized Canonical Discriminant Function Coefficients

\begin{tabular}{|c|c|c|c|c|c|}
\hline $\mathrm{y}$ & $\mathrm{X}_{1}$ & $\mathrm{X}_{2}$ & $\mathrm{X}_{3}$ & $\ldots$ & $\mathrm{X}_{7}$ \\
\hline 1 & 0.108 & 0.290 & 0.538 & $\ldots$ & 0.577 \\
\hline
\end{tabular}

Table I shows that, according to the standardized discriminant function coefficients, standardized Fisher discriminant function is:

$$
\begin{aligned}
Z= & 0.108 X_{1}+0.290 X_{2}+0.538 X_{3}+0.087 X_{4} \\
& +0.338 X_{5}+0.166 X_{6}+0.577 X_{7}
\end{aligned}
$$

TABLE II Non-standardized Canonical Discriminant Function Coefficients

\begin{tabular}{|c|c|c|c|c|c|c|}
\hline $\mathrm{y}$ & $\mathrm{X}_{1}$ & $\mathrm{X}_{2}$ & $\mathrm{X}_{3}$ & $\ldots$ & $\mathrm{X}_{7}$ & constant \\
\hline 1 & 0.073 & 1.531 & 1.236 & $\cdots$ & 1.597 & -0.926 \\
\hline
\end{tabular}

From Table II, discriminant function can be constructed as follows:

$$
\begin{aligned}
Z= & 0.073 X_{1}+1.531 X_{2}+1.236 X_{3}+0.015 X_{4} \\
& +0.235 X_{5}+0.122 X_{6}+1.597 X_{7}-0.926
\end{aligned}
$$

TABLE III Classification Function Coefficients

\begin{tabular}{|c|c|c|c|c|c|c|}
\hline $\mathrm{y}$ & $\mathrm{X} 1$ & $\mathrm{X} 2$ & $\mathrm{X} 3$ & $\cdots$ & $\mathrm{X} 7$ & constant \\
\hline 0 & 0.611 & - & 4.788 & $\ldots$ & 2.753 & -3.709 \\
\hline 1 & 0.458 & - & 2.195 & $\cdots$ & -0.597 & -1.767 \\
\hline
\end{tabular}

Table III shows that, we can get Bayes discriminant function according to the classification function coefficients. ST group:

$$
\begin{aligned}
\mathrm{Z}_{1} & =0.458 \mathrm{X}_{1}-5.258 \mathrm{X}_{2}+2.195 \mathrm{X}_{3}-0.015 \mathrm{X}_{4}-0.035 \mathrm{X}_{5} \\
& +0.133 \mathrm{X}_{6}-0.597 \mathrm{X}_{7}-1.767
\end{aligned}
$$

TABLE IV Eigenvalues

\begin{tabular}{|c|c|c|c|c|}
\hline Function & Eigenca-lues & $\begin{array}{c}\text { The } \\
\text { Percentage } \\
\text { of Variance }\end{array}$ & $\begin{array}{c}\text { The } \\
\text { Percentage of } \\
\text { Accunulation }\end{array}$ & $\begin{array}{c}\text { Canonical } \\
\text { correlatio-n }\end{array}$ \\
\hline 1 & 1.129 & 100.0 & 100.0 & 0.728 \\
\hline
\end{tabular}

If you need to use Bayes discriminant function, enter values of the independent variables in two discriminant function. Determine the group by getting greater function value. Use a non-standardized discriminant function to calculate the discrimination value, input variables, then identify groups by comparing the Z-scores obtained and threshold. This article uses non-standardized discriminant function as criteria namely for convenience:

$$
\begin{aligned}
\mathrm{Z}= & 0.073 \mathrm{X}_{1}+1.531 \mathrm{X}_{2}+1.236 \mathrm{X}_{3}+0.015 \mathrm{X}_{4}+0.235 \mathrm{X}_{5} \\
& +0.122 \mathrm{X}_{6}+1.597 \mathrm{X}_{7}-0.926 \\
\mathrm{Z}_{0}= & 0.611 \mathrm{X}_{1}-2.046 \mathrm{X}_{2}+4.788 \mathrm{X}_{3}+0.015 \mathrm{X}_{4} \\
& -0.459 \mathrm{X}_{5}+0.389 \mathrm{X}_{6}-2.753 \mathrm{X}_{7}-3.709
\end{aligned}
$$

Then the mean of each financial indicators, which belongs to two groups of sample data (non-ST group and ST group), were substituted into non-standardized discriminant function to obtain the mean center of gravity of non-ST and ST sample companies. Namely, non-ST group's center of gravity values $Z_{1}=1.05$; ST group's center of gravity value $\mathrm{Z} 2=$ 1.05. Determine best decision point according to completely symmetrical principle, namely: $\mathrm{Z} *=\left(\mathrm{Z}_{1}+\mathrm{Z}_{2}\right)=0.00$, when $\mathrm{Z}$ $<Z^{*}$, it is judged as ST company, otherwise, when $\mathrm{Z}>\mathrm{Z} *$, it is judged as non-ST company.

\section{Empirical Analysis}

\section{A. Model validation}

Take the data samples of randomly selected 20 listed companies in Shanghai and Shenzhen (10 ST and 10 non-ST companies) into discriminant function, the text results showed that: judgment on 10 non-ST is correct, the correct rate is $100 \%$; the judgment on $10 \mathrm{ST}$ companies, 7 companies' is correst, the correct rate is $70 \%$, false positive rate is $30 \%$, the correct rate of the overall model is $85 \%$, indicating that the model still have good judgement ability. So you can use the model for financial distress forecasting of listed companies.

\section{B. Jilin Province listed companies financial crisis early warning and assessment}

Based on selected data sample of 31 listed companies in Jilin Province (2011, 2012), using the established model of Financial Distress Prediction analyze and forecast financial situation of listed companies in Jilin Province, obtain Z - score 
distribution of a listed company in Jilin Province by calculating as shown in Table V:

Table V shows that in 2011,the Z-Score of two listed companies is too low, the probability of financial crises is high, which accounted for 9.7\%.Additionally,in 2011, there are four high Z-score of listed companies, while in 2012 there are eight. In general, the indicators of Financial Early Warning Model are generally positive indicators, so the higher Z-score, the more secure financial situation of enterprises. But too high Z-score may mean low resource utilization efficiency, which should attract attention.

TABLE V The Z-score Distribution Listed Companies in Jilin

\begin{tabular}{|c|c|c|c|c|}
\hline \multirow{2}{*}{$Z$-score range } & \multicolumn{2}{|c|}{ Number of range } & \multicolumn{2}{c|}{ Proportion } \\
\cline { 2 - 5 } & 2011 & 2012 & 2011 & 2012 \\
\hline$Z<-1.05$ & 2 & 3 & $6.5 \%$ & $9.7 \%$ \\
\hline$\lceil-1.05,1.05 〕$ & 25 & 20 & $80.7 \%$ & $64.5 \%$ \\
\hline$Z>1.05$ & 4 & 8 & $12.8 \%$ & $25.8 \%$ \\
\hline Total & 31 & 31 & $100 \%$ & $100 \%$ \\
\hline
\end{tabular}

Obtain changes in financial position of listed companies in Jilin by analysising the Z-score changes from 2011 to 2012, as shown in Table VI:

TABLE VI Changes in Financial Crisis Situation of Listed Companies in Jilin

\begin{tabular}{|c|c|c|}
\hline Financial position & Number of companies & Proportion \\
\hline Maintain normal & 12 & $38.7 \%$ \\
\hline In crisis & 11 & $35.5 \%$ \\
\hline Improve & 5 & $16.1 \%$ \\
\hline Deterioration & 3 & $9.7 \%$ \\
\hline Total & 31 & $100 \%$ \\
\hline
\end{tabular}

As can be seen from Table VI, there are 12 company's financial position remained normal, accounting for 38.7\%; there are 11 companies still exist hidden crisis, accounting for $35.7 \%$; 5 company's financial situation has improved, accounting for $16.1 \%$; three of the company's financial condition deteriorated from the normal state to the financial crisis, accounting for $9.7 \%$. On the whole, in 2011, the Z-score of 15 companies is higher than 0(financial position is expected to normal).Z-score of 16 companies less than 0 (there exists the possibility of the financial crisis), Which has two less than -1.05 , that is a high likelihood of financial crises. $\mathrm{Z}$-score of 17 companies is higher than 0 in 2012, financial projections is normal. Z-score of 14 companies less than 0 , there exists the possibility of financial crisis, 3 is less than -1.05 , a high likelihood of financial distress.

Study enterprise financial crisis also should consider the $\mathrm{Z}$-score fluctuations. If the Z-score of each company keep a certain value each year, only occurs small amplitude fluctuations, indicating that the company's financial situation is relatively stable, the possibility of financial crisis is relatively small. If Z-score of the company has relatively large fluctuations each year, illustrate that there are more factors of instability in the company's production and management process, which will be the company's hidden financial crises. Table VII analysises Z-score changes of company each year:

Learn from Table VII, the magnitude of changes of 14 companies are less than $50 \%$ (The magnitude of changes within normal range account for $45.2 \%$ ); Changes in amplitude of four companies are $50 \%$ to $100 \%$, the change amplitude is slightly higher, accounting for $12.9 \%$.The Z-score changes of 13 companies are more than $100 \%$. The changes in amplitude are larger, which accounting for $41.9 \%$, has a high potential of financial crisis. Greater volatility of $Z$ value illustrates many unstable factors in business activities of the company. The factors make the company's financial position at risk. Probably some uncertain factors lead to financial crises of the company. Considering the fluctuations of Z-score is also very important for analysising the company's financial situation.

TABLE VII Z-scores change of Listed Companies in Jilin 2011-2012

\begin{tabular}{|c|c|c|}
\hline $\mathrm{Z}$-score variation width & Number of companies & Proportion \\
\hline Changes in amplitude $\leq 50 \%$ & 14 & $45.2 \%$ \\
\hline $50 \%<$ change rate of $\leq 100 \%$ & 4 & $12.9 \%$ \\
\hline Changes in amplitude $>100 \%$ & 13 & $41.9 \%$ \\
\hline Total & 31 & $100 \%$ \\
\hline
\end{tabular}

\section{Conclusions and Policy Recommendations}

\section{A. Conclusions}

The characteristics of Financial Distress Prediction and empirical analysis shows that there are indications for listed companies before the financial crisis occurred. Analysis the Zscore and its financial indicators you can make financial distress forecasting. Analysis financial position of the listed company in Jilin, we can draw the following conclusion:

\section{1) reasonable and effective for model building}

First,select enough samples. The more adequate sample date, the better the model. Second, make adjustments over time to ensure the model accurate and effective. Moreover, univariate and multivariate models are combined, quantitative and qualitative analysis are combined, during the financial distress forecasting, which can analyze the ture level of the company's financial condition more comprehensively.

2) the overall financial situation of listed companies in Jilin Province is common

By analyzing the financial situation of the 31 listed companies in Jilin, half of the Z-scores is less than 0 from 2011 to 2012, has the probability of occurring financial crisis. The proportion in 2012 is $45 \%$, slightly fewer than 2011, but is still higher ratio. While most of listed companies in Jilin Province in 2012 get profit, but listed companies have greatly increased size of debts, which constantly swallowing profits, and the main source of profit come from non-core business revenue, quality of the company's operations is poor, the risk 
of financial crisis increase. Jilin Province has relatively backward economic and technological strength and located in the northeast old industrial base is the main reason. High-tech industries and services are still in a relatively early stage of development, we can see from Z-score of listed companies in Jilin that the overall financial situation is common.

\section{3) fluctuations of financial position of listed company in Jilin}

The listed companies in Jilin province, which Z-score fluctuations over 50\%, reach 54.8\% from 2011 to 2012, indicate that many of the company's financial situation is very unstable and greatly influenced by uncertain factors. High financial fluctuations greatly increase the risk of the company's financial risk. We can not ignore the Z-score fluctuations.

\section{B. Policies and proposals}

Listed companies generally develop good in China, which is an important power source of economic growth. Through analysis, we can see that there are many financial crisis risks of listed companies in Jilin Province, which should cause the managers of companies great attention: take active measures, establish financial early warning mechanism and prevent financial risks.

Listed companies in Jilin should rational allocate resources, promote the adjustment of industrial structure, promote optimization and upgrading, adapt to market needs.
Jilin's industrial structure should be more rational layout, make full use of the advantages of the various regions, conduct a comprehensive and balanced industrial development. Pay more attention and support the development of emerging industries. Traditional industries should continue to become bigger and stronger.

Listed companies should pay attention to the importance of the main business, improving the efficiency of the company's management, enhance the company's competitiveness in the market. Always pay attention to changes of financial indicators, avoid the possibility of a financial crises.

\section{References}

[1] Man Wang, Kunrong Li, Empirical analysis on early warning modelof financial crisis of Liaoning listed company-from perspective of Z-score model, Journal of Dalian Maritime University, 2009

[2] JiLu Liu, build financial early warning model based on Fisher discriminant analysis-financial condition evaluation of listed company in Zhejiang. Accounting Monthly, 2011

[3] Hui Xuan Gao, Applied Multivariate Statistical Analysis, Peking University Press, 2005

[4] Shinong Wu, xian Yi Lu, A Study of Models for Predicting Financial D istress in Chins's Listed Companies. Economic Research Journal, 2001

[5] Han Zheng, Corporate financial distress model Analysis Co-Operative Economy \& Science, 2009 